\title{
Recerca geològica i geoambiental per les comarques del Berguedà i del Solsonès: des de Berga i Capolat a: Trasserra, Taravill, Vilella i a I’Espunyola
}

Josep Maria Mata-Perelló

Joaquim Sanz Balagué

\section{XARAGALL \\ REVISTA DE CIÈNCIES DE LA CATALUNYA CENTRAL} n. 4

ABRIL 2014 


\title{
RECERCA GEOLÒGICA I GEOAMBIENTAL PER LES COMARQUES DEL BERGUEDÀ I DEL SOLSONÈS: DES DE BERGA I CAPOLAT A: TRASSERRA, TARAVILL, VILELLA I A L'ESPUNYOLA
}

\author{
Josep Maria Mata-Perelló \\ Museu de geologia Valentí Masachs, Escola Politècnica Superior d'Enginyeria de Manresa \\ (EPSEM), Universitat Politècnica de Catalunya · BarcelonaTech (UPC), 08272 Manresa, Spain
}

Joaquim Sanz Balagué

Departament d'Enginyeria Minera i Recursos Naturals (EMRN), Escola Politècnica Superior d'Enginyeria de Manresa (EPSEM), Universitat Politècnica de Catalunya - BarcelonaTech (UPC), 08272 Manresa, Spain

Paraules clau: Avant-País Plegat; materials cenozoics; materials oligocènics

\section{Resum}

Itinerari realitzat el dia 23 de març del 2013. El recorregut del present l'itinerari discorrerà per la vorera septentrional de la Depressió Geològica de l'Ebre, tot i que molt prop del Pirinenc, pels trams inicials.

Així, en els primers trams es circularà per la denominada zona de I'Avant-País Plegat (corresponent a la vorera septentrional de l'esmentada depressió). Concretament, s'hi circularà entre Berga i les immediacions de Capolat.

Després, tot el recorregut es farà íntegrament per la Depressió Geològica de I'Ebre; i més concretament, als trams finals per la seva Depressió Central, especialment pels voltants de I'Espunyola. Per d'altra banda, el recorregut transitarà per dues de les comarques que formen part de la Catalunya Central, la del Berguedà i la del Solsonès (tot i que en el cas d'aquesta darrera serà molt puntual). 


\section{Objectius fonamentals d'aquest itinerari}

Els objectius fonamentals que es pretenen aconseguir en aquest itinerari geològic $\mathrm{i}$ geoambiental, són els següents:

1. Observació dels afloraments dels materials cenozoics que formen part de la Zona de I'Avant-País Plegat, que trobarem a diversos indrets del recorregut de l'itinerari, com pels voltants del Santuari de Queralt; i més concretament entre les poblacions de Berga i Capolat.

2. Observació de la Depressió Geològica de l'Ebre, per la qual es circularà entre Berga i el fi del recorregut. Tot i que els primers trams es situen dintre de l'Avant-País Plegat.

3. Observació dels afloraments dels materials cenozoics que formen part de la Depressió Geològica de l'Ebre (i tanmateix de la Zona de l'Avant-País Plegat). Aquests materials els tallarem al llarg de tot el recorregut de l'itinerari. Fonamentalment, es tracta dels materials del Complex Al/luvial de Berga (de caràcter detrític) i dels de la Formació Solsona (amb gresos i calcolutites ocres).

4. Observació dels materials oligocènics del Sistema Al/luvial de Berga, que trobarem a diferents indrets del recorregut. Aquests materials, i especialment els postorogènics, cobriran ocasionalment a les estructures anteriors.

5. Estudi i descripció de diferents mineralitzacions, i també de les explotacions situades al llarg del recorregut.

6. Observació de les explotacions mineres (antigues i actuals), relacionades amb les mineralitzacions anteriors. I alhora, observació de l'impacte sobre el Medi Natural, produït per les explotacions anteriors; i si s'escau de les restauracions dutes a terme per tal d'eliminar-lo.

7. Observació dels diferents indrets relacionats amb el patrimoni geològic i amb el patrimoni miner, que es vagin trobant al llarg del recorregut del present itinerari.

\section{Antecedents bibliogràfics}

En relació amb el recorregut del present itinerari, existeixen alguns antecedents parcials, especialment relatius als primers trams del recorregut, entre la ciutat de Berga i el Santuari de Queralt. Entre aquests antecedents, farem esment dels següents: Masachs et altri (1981); i també de Mata-Perelló (1995, 1996, 1997a, 1997, 2004, 2007a, 2007b, 2010, 2011 i 2012). En canvi, pel que fa al recorregut entre el Capolat i L'Espunyola, no coneixem cap antecedent, essent el present una primícia.

Per d'altra banda, en canvi, farem esment de diversos treballs, de caràcter geològic general i regional, com són els següents: GUIMERÀ et altri (1992), i RIBA et altri (1976). Igualment, es pot fer esment de les recents publicacions de l'IGME (1994a i 1994b).

I, pel que fa a l'estudi de les mineralitzacions situades dintre de l'àrea per la qual discorre I'itinerari, farem esment d'un altre treball nostre, concretament del Mata-Perelló (1991). També, en treball més monogràfic, es poden trobar antecedents a Mata-Perelló (1984). També hi ha un antecedent al treball de Mata-Perelló i Sanz Balagué (1991). 
Tots aquests treballs, i d'altres, figuraran degudament relacionats per ordre alfabètic, i per data de publicació, dintre de l'apartat d'aquest treball dedicat a les referències bibliogràfiques, al qual ens remetem.

\section{Descripció del recorregut de l'itinerari}

El recorregut del present itinerari, s'iniciarà a la localitat de Berga, per tal d'anar cap a ponent, per la carretera BV - 4241 Així s'arribarà a les immediacions del túnel (la "Mina"). Abans d'arribar-hi, es faran diverses aturades.

Després, poc abans d'entrar a l'esmentat túnel, es trobarà la carretera local (sense numeració) que es dirigeix cap a Capolat. En aquest tram s'efectuarà una nova aturada, poc abans d'arribar a la darrera població esmentada.

Després, el recorregut es dirigirà cap als llogarrets de Trasserra i de Taravill. En aquest tram s'efectuaran dues noves aturades. Posteriorment es farà una fillola, tot anant cap a Vilella (Solsonès). En aquest tram es realitzaran dues noves aturades.

I, finalment, el recorregut es dirigirà cap a la població de I'Espunyola, arribant a la carretera C 26. En aquest tram es faran diverses aturades, finalitzant el recorregut prop del darrer poble esmentat.

\section{Advertiment previ}

Com en altres recorreguts de recerca geològica i mineralògica ..., si es disposa del temps suficient, poden efectuar-se passant per totes les parades i filloles. En cas contrari, recomanem prescindir de les anomenades parades - condicionals.

També recomanem de cercar la informació més adient, sobre els trams a recórrer mitjançant camins de terra, o de pista.

Per d'altra banda, recomanem tenir una cura extrema de la natura, evitant qualsevol forma d'agressió sobre ella, o de fer-n'hi un mal ús del que en ofereix la nostra mare Terra.

\section{Descripció de l'itinerari}

En aquest recorregut hem situat, com ja és habitual en tots els altres itineraris de recerca, una sèrie d'estacions o de parades, que anirem veient a continuació. En cada cas, els hi donarem una denominació que podrà correspondre a algun paratge proper.

Per d'altra banda, en cadascuna de les parades, indicarem entre parèntesi el número del "Mapa Topográfico" del "Instituto Geográfico y Catastral de España", a escala 1:50.000, on es troba situada la parada considerada. 
En aquesta ocasió, utilitzarem els següents fulls topogràfics: 292 (o de Sant Llorenç de Morunys) i 293 (dit de Berga). Així doncs, la relació de les aturades que composen el recorregut del present itinerari, és la següent:

\subsection{Parada 1. Voltants del bar La Cabana, (Terme Municipal De Berga, comarca del Berguedà). (Full 293).}

Tot i que el recorregut l'haurem iniciat a la ciutat de Berga, al bell mig del Berguedà, caldrà sortir per la carretera local BV - 4241 (la qual condueix cap a Sant Llorenç de Morunys). Poc després de deixar la ciutat, en una carretera ascendent, arribarem a l'indret on hi ha el Bar de la Cabana. Aquí farem la primera aturada, a uns $2 \mathrm{Km}$ i escaig de la ciutat.

L'indret de la parada es troba situat per sobre de la ciutat de Berga, entre afloraments dels materials detrítics terciaris que pertanyen als sectors més meridionals del Mantell del Cadí-Port del Comte, del Sistema Pirinenc. Aquests materials, on ara ens trobem, formen part dels denominats conglomerats de Queralt.

Tot i així, des del principi del recorregut es circula per entre la Formació Berga, constituïts per calcolutites, gresos, i conglomerats, la qual forma part del Sistema Al/luvial Superiors de Berga, i es troben situats a la Zona de l'Avant-país plegat, de la Depressió Geològica de l'Ebre. Aquests materials es troben afectats pel proper encavalcament principal sud-pirinenc (GUIMERÀ et altri, 1992), i es troben clarament verticalitzats, presenten un clar cabussament cap al sud.

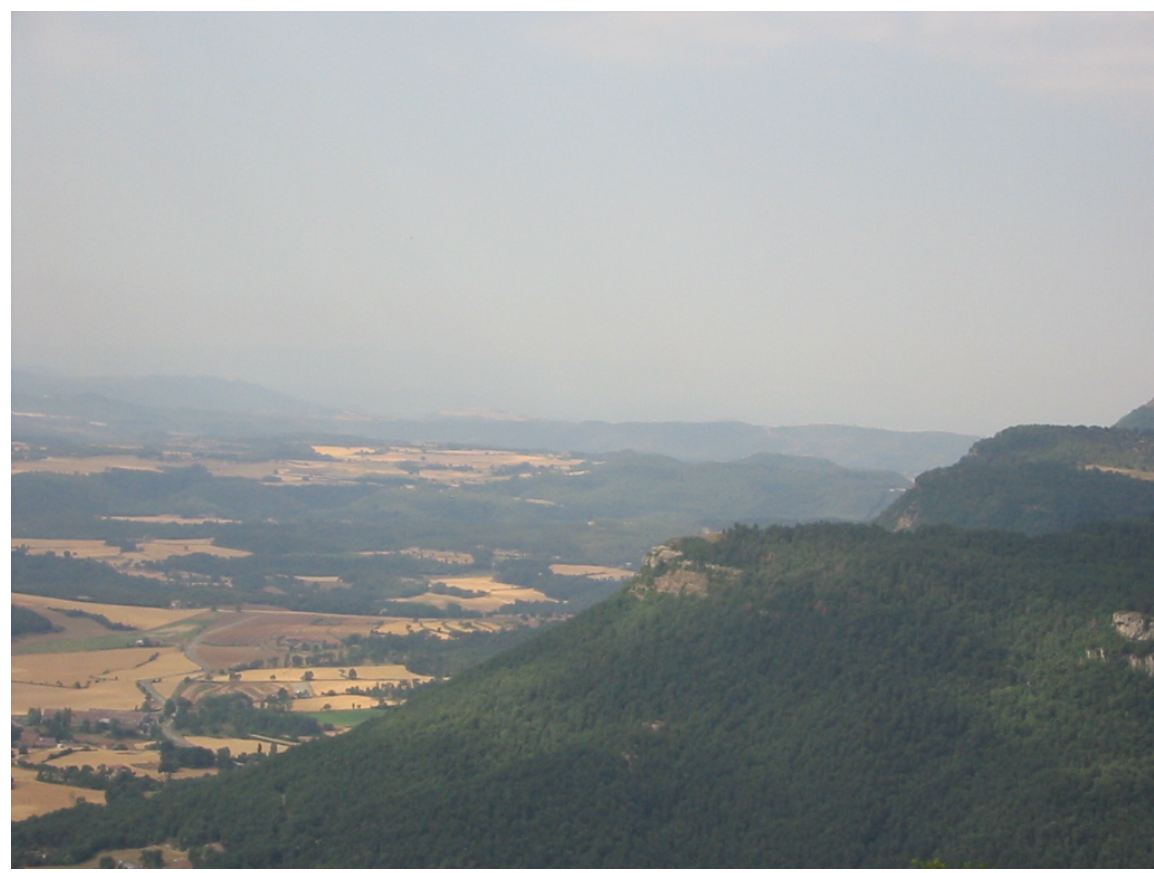

FOTOGRAFIA 1. Contrast entre la Depressió Geològica de l'Ebre i el Mantell del Cadí 
Per d'altra banda, des d'aquest indret, i mirant cap els voltants de Berga, i cap al Sud de la població, es pot gaudir d'una bona panoràmica d'aquest sector de la Depressió Geològica de I'Ebre. Així, es pot veure ben clar el denominat Sinclinal de Berga. (fotografia 1).

\subsection{Parada 2. Carretera Bv-4241, immediacions del km 2, (terme municipal de Berga, comarca del Berguedà). (full 293).}

Després de fer l'aturada anterior, cal agafar la carretera local que es dirigeix cap a Sant Llorenç de Morunys, la BV - 4241. En trobar aquesta carretera, en arribar a les immediacions del seu $\mathrm{Km} \mathrm{2,} \mathrm{farem} \mathrm{una} \mathrm{nova} \mathrm{aturada.} \mathrm{Així,} \mathrm{des} \mathrm{de} \mathrm{la} \mathrm{parada} \mathrm{anterior,} \mathrm{haurem} \mathrm{efectuat} \mathrm{un}$ recorregut molt proper als $2 \mathrm{Km}$.

En aquest recorregut, haurem estat circulant a la zona de contacte entre l'Avant - País Plegat i el Mantell del Cadí. Aquests materials pirinencs encavalquen als terrenys terrígens de la Formació Berga, constituïts per trams de gresos, calcolutites i conglomerats. Aquests darrers materials pertanyen a la Depressió Geològica de l'Ebre, situant-se dintre de I'Avant País Plegat, on estem ara situats.

Aquest encavalcament forma part de la Falla Sudpirinenca. Així, des d'on ara som, pot observar-se un bloc de les calcàries cenozoiques, formant part del flanc meridional de I'encavalcament, situat sobre els afloraments de la Formació Berga. FOTOGRAFIA 2.

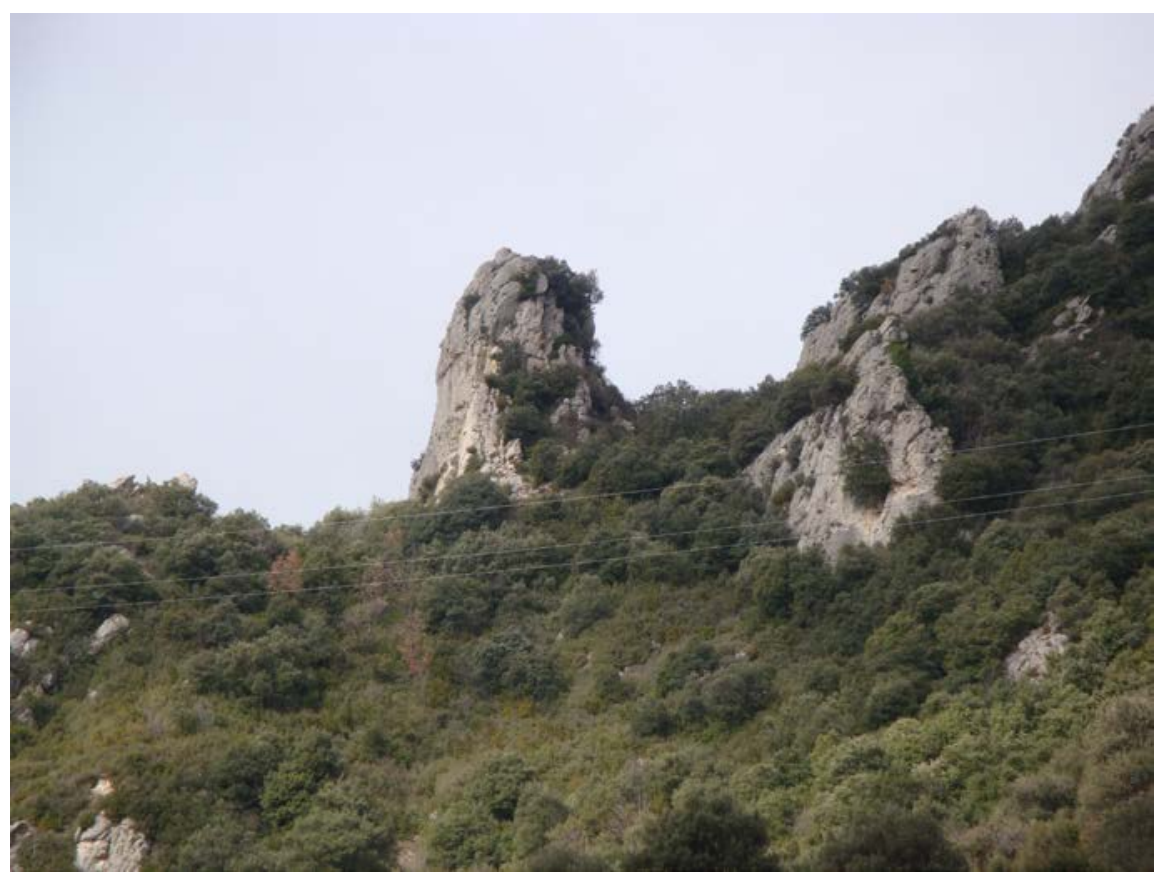

FOTOGRAFIA 2. Encavalcament del Mantell del Cadí sobre la zona de l'Avant País Plegat, zona Santuari de Queralt 


\subsection{Parada 3 - Condicional. Carretera BV-4241, immediacions dels km 6 - 7, ajuntament de Capolat, (terme municipal de Capolat, comarca del Berguedà). (Full 292).}

Des de la parada anterior, cal continuar cap a ponent per la carretera local BV - 4241. Poc després de realitzar la parada anterior, pot realitzar-se un altra, a uns $1-2 \mathrm{Km}$ de l'anterior, aproximadament.

En aquest recorregut, haurem trobat afloraments dels materials esmentats a les aturades anteriors. Així, a la vora de la carretera veurem els materials detrítics de la Formació Berga, els quals es situen a l'Avant - país Plegat, de la Depressió Geològica de I’Ebre. Sovint, per sobre d'aquests materials es van trobant els nivells carbonatats que formen part del Mantell del Cadí. Aquests materials encavalquen als anteriors.

Des d'aquest indret, mirant cap al sud, es poden veure els relleus tabulars de Capolat, des de les immediacions del seu Ajuntament. Aquests relleus estan formats per afloraments de materials detrítics (fonamentalment conglomerats), postorogènics. Aquests materials constitueixen els relleus de les anomenades "tres Maries".( fotografia 3).

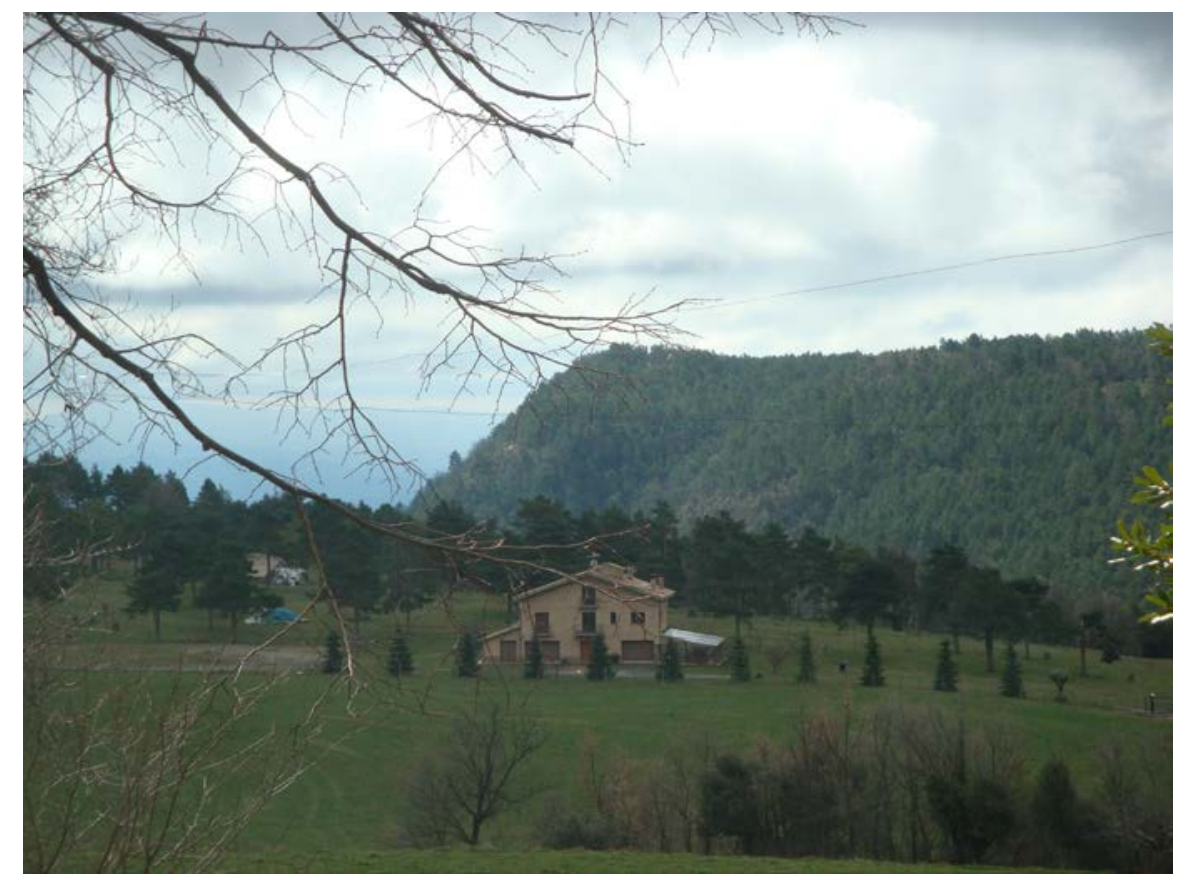

Fotografia 3. Relleus tabulars de Capolat, des de les immediacions del seu ajuntament, proper a Sant Martí

\subsection{Parada 4 - Condicional. carretera local a Capolat, trencall de la Mare de Déu dels Tossals, (terme municipal de Capolat, comarca del Berguedà). (Full 292).}

Des de la parada anterior, cal continuar cap a ponent per la carretera local BV - 4241. Però, en arribar al túnel (a la denominada "mina"), ens caldrà agafar la carretera local que es dirigeix cap el poblet de Capolat. En arribar a les immediacions del trencall de la Mare de deu dels Tossals, farem una nova aturada, si s'escau, a uns $7 \mathrm{Km}$ de l'anterior. 
En aquest recorregut, hem anat trobant afloraments dels materials esmentats a les aturades anteriors; és a dir: nivells de conglomerats i gresos. Aquests materials pertanyen al Complex Al.luvial de Berga, de l'Oligocè.

Des d'aquest indret, es pot gaudir d'una bona observació dels relleus de Queralt, mirant cap a I'Est d'on ara som.

\subsection{Parada 5. Carretera local a Capolat, Font de Sant Pere, (Terme Municipal De Capolat, comarca del Berguedà). (Full 292).}

Després de realitzar la parada anterior, cal continuar per la carretera local (sense numeració) que es dirigeix cap el poblet de Capolat. Després de superar-lo, ens caldrà seguir cap a ponent, per tal d'anar cap el llogarret de Trasserra. Poc abans d'arribar-hi, trobarem a la dreta de la carretera una fonteta. Aquí, farem una nova aturada, després de recórrer uns $5-6 \mathrm{Km}$ més, des de la darrera aturada.

En aquest tram, hem anat trobant afloraments dels conglomerats postorogènics de l'Oligocè. Els quals pertanyen al Complex Lacustre de Berga. Normalment, aquests materials són gairebé horitzontals, com en aquest indret. (fotografia 4).

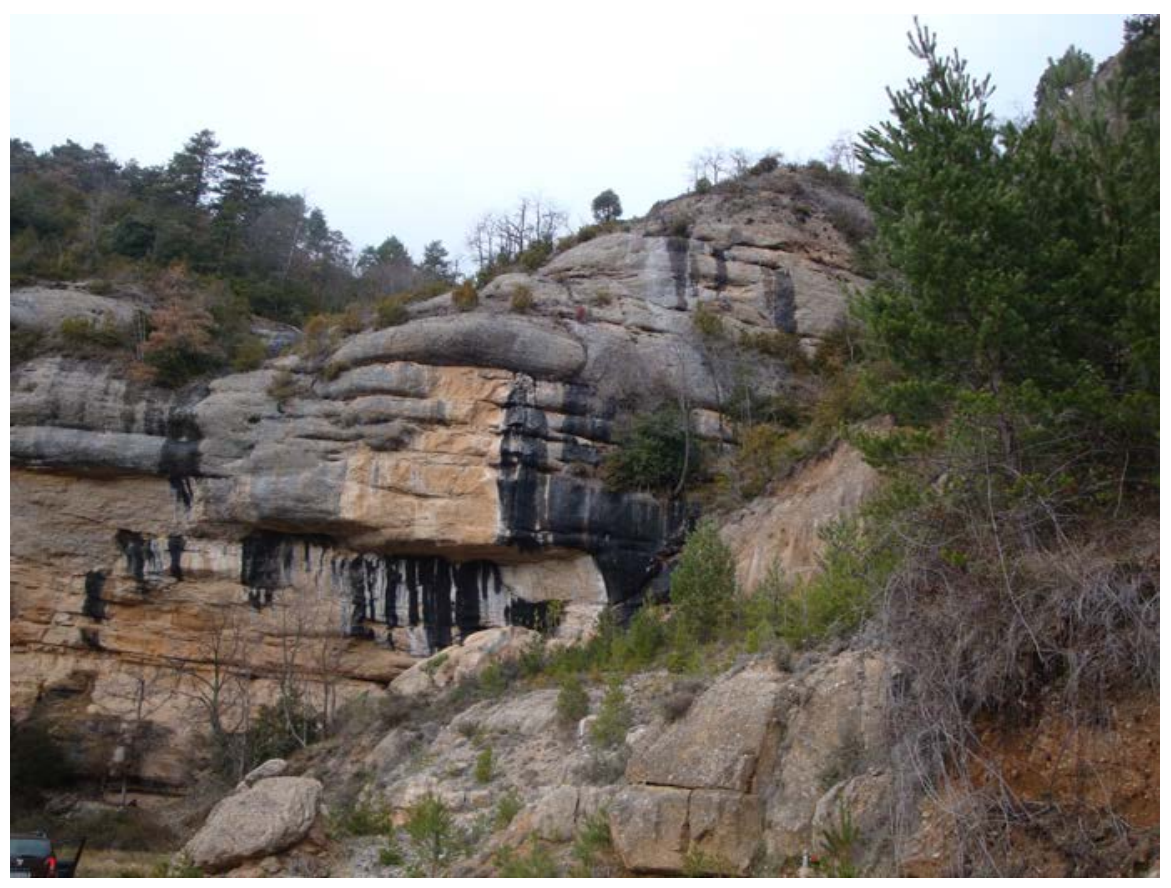

Fotografia 4 Afloraments gairebé horitzontals del conglomerats postorogènics. Font de Sant Pere, Capolat

Per d'altra banda, en aquest sector hi ha una font, en la qual brolla l'aigua. Aquesta eix en el contacte entre els nivells de conglomerats i uns nivells de calcolutites ocres. 


\subsection{Parada 6 - Condicional. Plans de Trasserra, (Taravill, terme municipal de Capolat, comarca del Berguedà). (Full 292).}

Després de realitzar la parada anterior, cal continuar per la carretera local, que es dirigeix cap a ponent. Així, aviat passarem per Trasserra, continuant ara capa Taravill. A uns $4-5 \mathrm{Km}$ de la parada anterior, entre els dos llogarrets, farem una nova aturada.

En aquest recorregut, hem anat trobant afloraments dels materials detrítics esmentats a les aturades anteriors. Aquests materials són gairebé horitzontals, formant un conjunt de relieves en cuesta. Precisament ara ens troben en una plana situada entre dos graons, per on circula la carretera.

Així, des de l'indret de l'aturada es pot veure aquesta plana, situada sobre la "cuesta" de Capolat i per sota de la "cuesta" del Tossal de Vilella. Entre ambdues es situa el Pla de Traserra, per on estem ara situats. (fotografia 5).

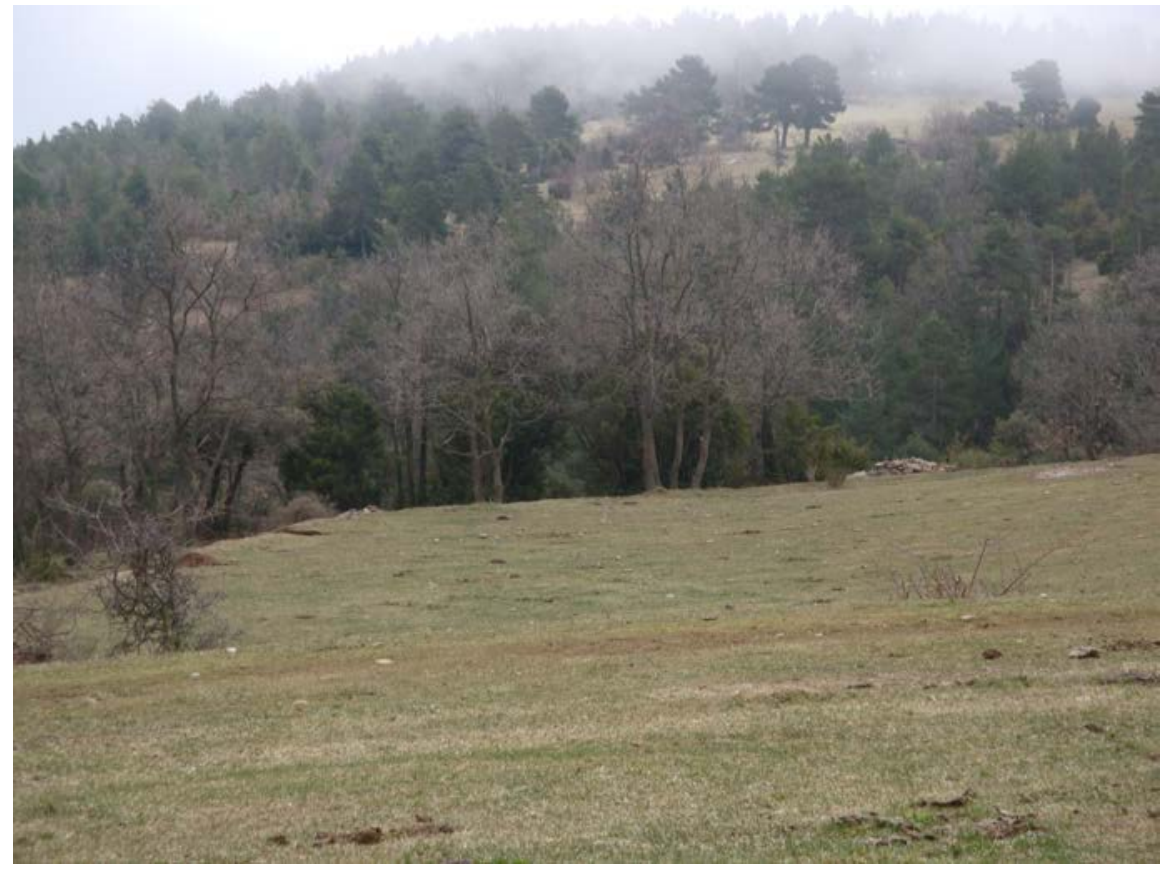

FOTOGRAFIA 5. El Pla de Trasserra

Cal dir, que existeixen plans similars pels voltants de Capolat i també pels de Taravill. Precisament més endavant circularem per aquests darrer.

\subsection{Parada 7. Inici de la carretera a Vilella (Taravill, terme municipal de Capolat, comarca del Berguedà). (Full 292).}

Després de fer l'aturada anterior, cal continuar per la carretera local, anant ara cap el poblet de Taravill. Poc després de superar-lo, arribarem al trencall de la carretera que es dirigeix cap el poblet solsonenc de Vilella. Poc després d'agafar aquesta carretera, podem fer una nova aturada, a uns $3 \mathrm{Km}$ de l'anterior. 
Com en els desplaçaments anteriors. En aquest, hem anat trobant afloraments dels conglomerats postorogènics de I'Oligocè. Aquest són ben visibles per sobre nostre, al Tossal de Vilella. Aquests materials pertanyen al Complex Al-luvial de Berga i son gairebé horitzontals.

Tot i així, en aquest indret, mirant cap al NW, podem gaudir d'una immillorable observació de la Serra de Busa, situada a I'altre cantó de la Vall de I'Aigua d'Ora. Així, veiem clarament, des $d^{\prime}$ aquest indret el Sinclinal de Busa. (fotografia 6).

I tanmateix, podem veure la Serra de Bastets, situada als seus peus, formant entre les dues una interessant discordança progressiva. No gaire visible des d'aquest indret. Tot i així, si que es ben visible la Serra de Bastets, situada als peus de la Serra de Busa, en una posició septentrional. (fotografia 7 ).

Cal fer esment que els conglomerats postorogènics que apareixen a la Serra de Busa, són perfectament equiparables, de la mateixa cronologia, dels que tenim sobre nostre, al Tossal de Vilella,

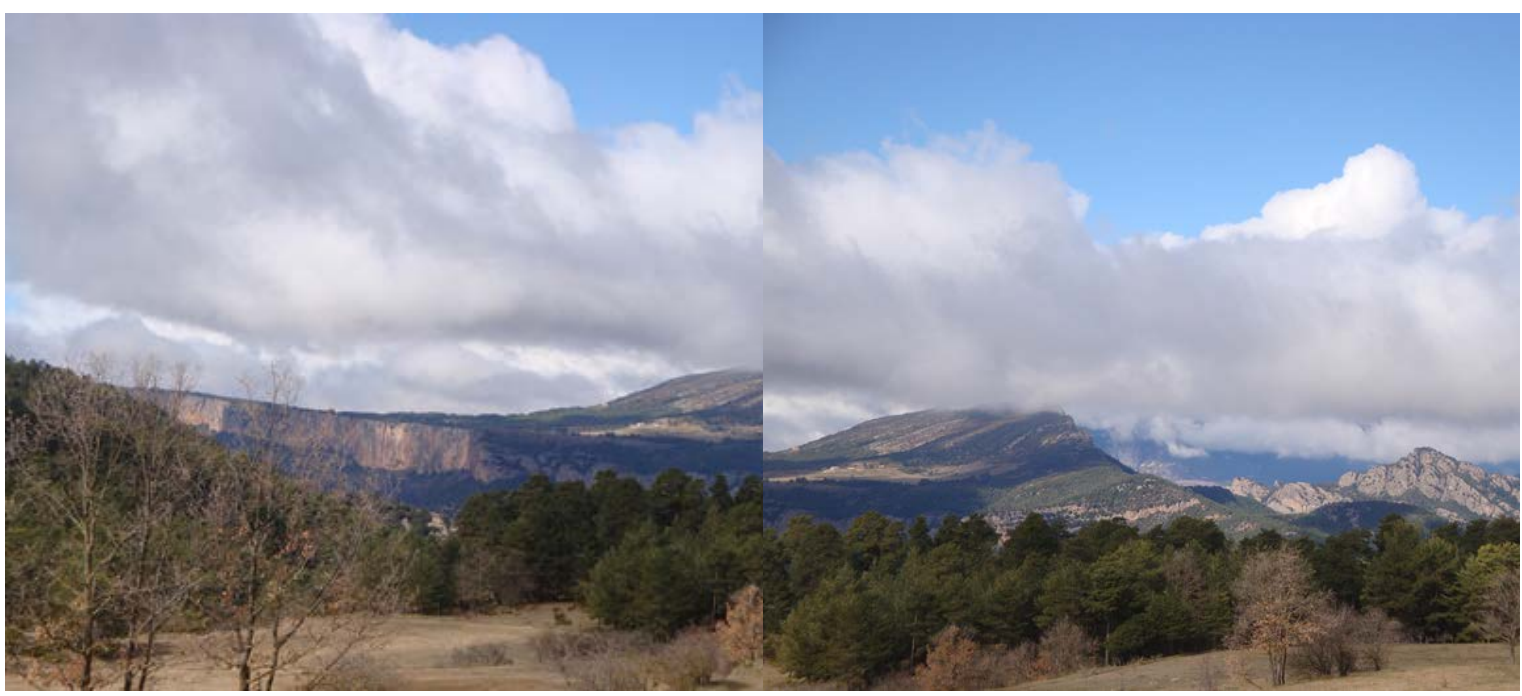

FOTOGRAFIA 6. Serra de Busa amb el Sinclinal de Busa FOTOGRAFIA 7. Serra de Busa i Serra de Bastets

Entre les dues hi ha una interessant discordança progressia, no totalment observable des d'aquest indret de l'inici de la carretera a Vilella

\subsection{Parada 8. Immediacions de Vilella, (Vilella, terme municipal de Navès, comarca del Solsonès). (Full 292).}

Després de fer la parada anterior, ens cal fer un recorregut anant cap a les immediacions del poblet de Vilella. Poc abans d'arribar-hi (a uns 0' 6 del llogarret), farem una nova aturada, a uns $1^{\prime} 4 \mathrm{Km}$ de l'aturada anterior.

En aquest recorregut, hem continuat trobant els materials que hem esmentat a la parada anterior. De fet, estem ara sota dels cim del Tossal de Vilella i es fan palesos per arreu els nivells dels conglomerats postorogènics de l'Oligocè, del Complex Al-luvial de Berga, que apareixen amb una estructura gairebé horitzontal. 
Des d'aquest indret, mirant cap a ponent (una mica cap el WNW) es poden veure els relleus de la Serra de Busa, que ja hem vist a l'aturada anterior. Ara des d'aquí, es veu molt be el Sinclinal de Busa. (fotografia 8).

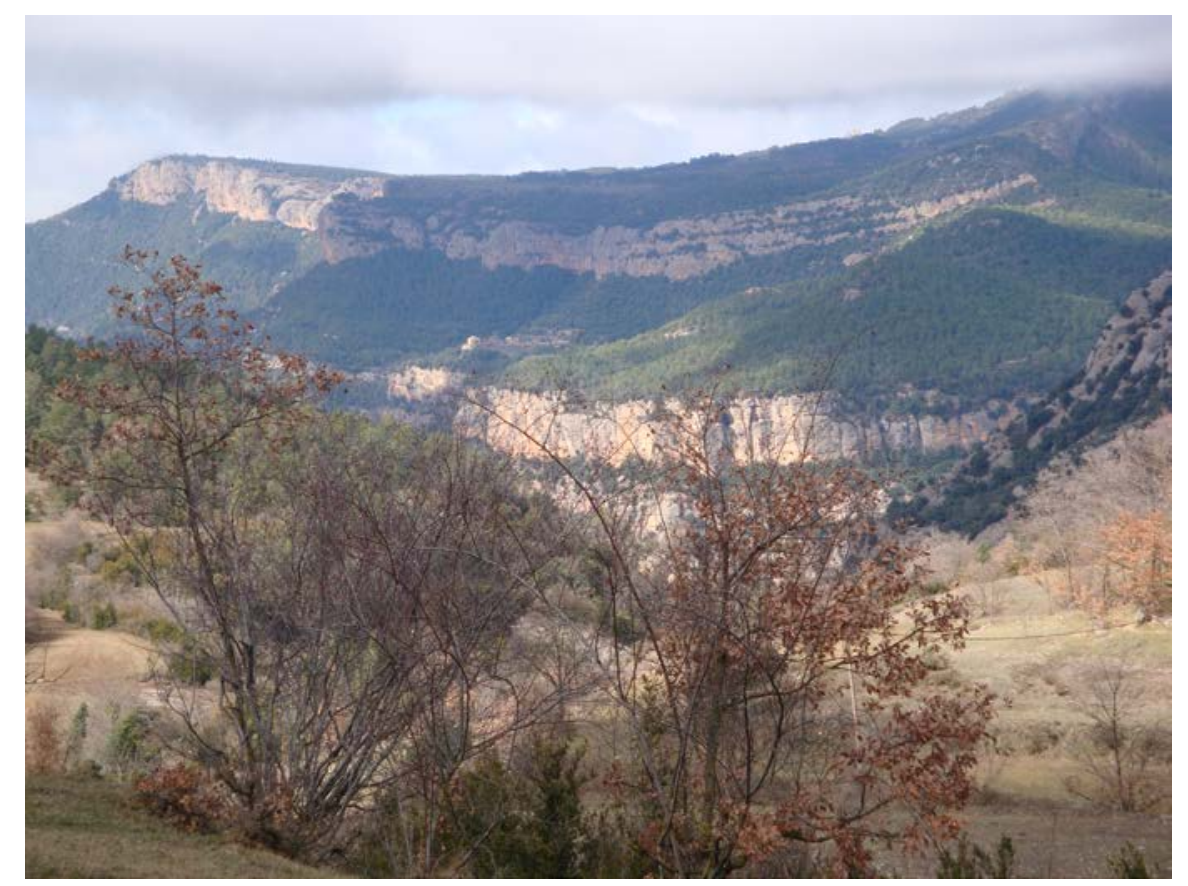

FOTOGRAFIA 8. La Serra de Busa (amb el Sinclinal de Busa) des de les immediacions de Vilella

\subsection{Parada 9. Inici de la baixada del malpas cap a Espunyola, (Taravill, terme municipal de Capolat, comarca del Berguedà). (Full 292).}

Després de fer la parada anterior, cal retornar cap a les immediacions de Taravill, tornant al Berguedà. Des d'aquí, ens convindrà seguir per la carretera local (sense numeració), per tal d'anar apropant-nos cap a Espunyola. Poc a poc començarem a baixar. Quasi a l'inici de la baixada pel Malpas podem fer una nova aturada.

En aquest recorregut, hem anat trobant afloraments dels materials esmentats a les aturades anteriors. De fet, ara estem sobre un aflorament dels nivells detrítics del Complex Al-luvial de Berga. Aquests materials oligocènics, formen aquí un graó, que forma part de la coneguda "cuesta" de Capolat. Així, des de la parada anterior, hem sortit dels peus del Tossal de Vilella, hem recorregut part del pla de Taravill, situat entre les dues "cuestes" i ara estem sobre del primer graó.

Des d'aquest indret, es pot gaudir d’una bona observació d’aquest graó, que s'aixeca per sobre de l’Espunyola. (fotografia 9). 


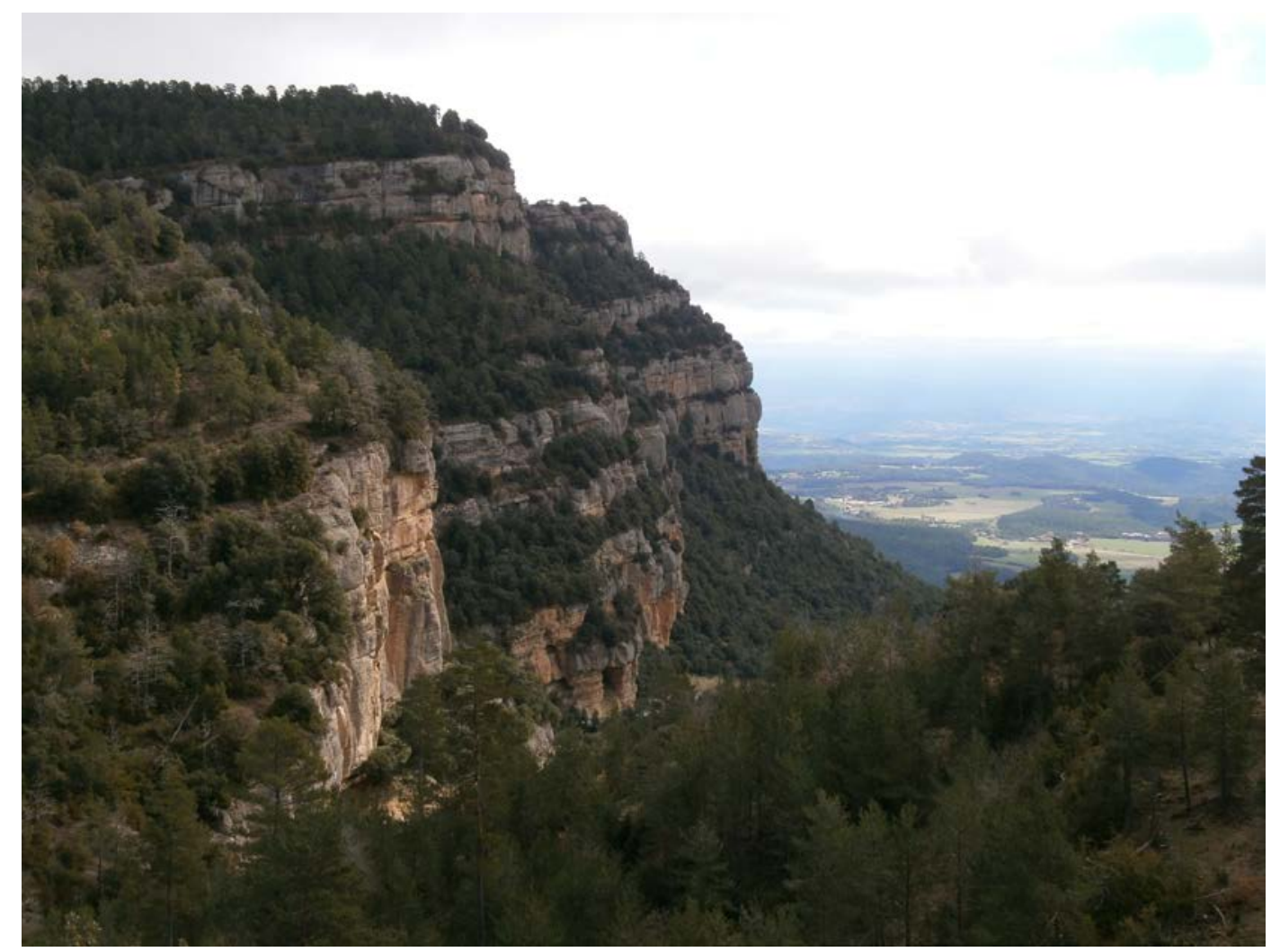

FOTOGRAFIA 9. La "cuesta" de Capolat, des del malpas, baixant cap a Espunyola

\subsection{Parada 10. Immediacions de Sant Sadurni del Cint, carretera de Capolat a I’Espunyola, El "Torm De Sant Sadurní", (Sant Sadurní del Cint, terme municipal de I’Espunyola, comarca del Berguedà). (Full 292).}

Després de fer la parada anterior, cal continuar baixant per la carretera (ara cimentada) que poc a poc es va apropant cap a l'Espunyola. Poc abans d'arribar a Sant Sadurní del Cint, podem fer una nova aturada, just en un revol. Així, des de la parada anterior, haurem efectuat un recorregut proper als $3 \mathrm{Km}$.

En aquest recorregut, hem anat trobant afloraments dels materials detrítics esmentats a les darreres aturades, els quals pertanyen al Complex Al-luvial de Berga. Es tracta de nivells de conglomerats, gresos i calcolutites. Poc a poc, cap a les parts baixes del recorregut, comencen a preponderar aquests darrers materials. Així, poc a poc anem passant del complex anterior als afloraments de la Formació Solsona, que ja predominen on som ara.

En aquest indret es pot veure un torm; és a dir: un fragment d'una roca més dura, interestratificat entre roques més toves, erosionat ui que s'ha conservat individualitzat del conjunt.( fotografia 10). 


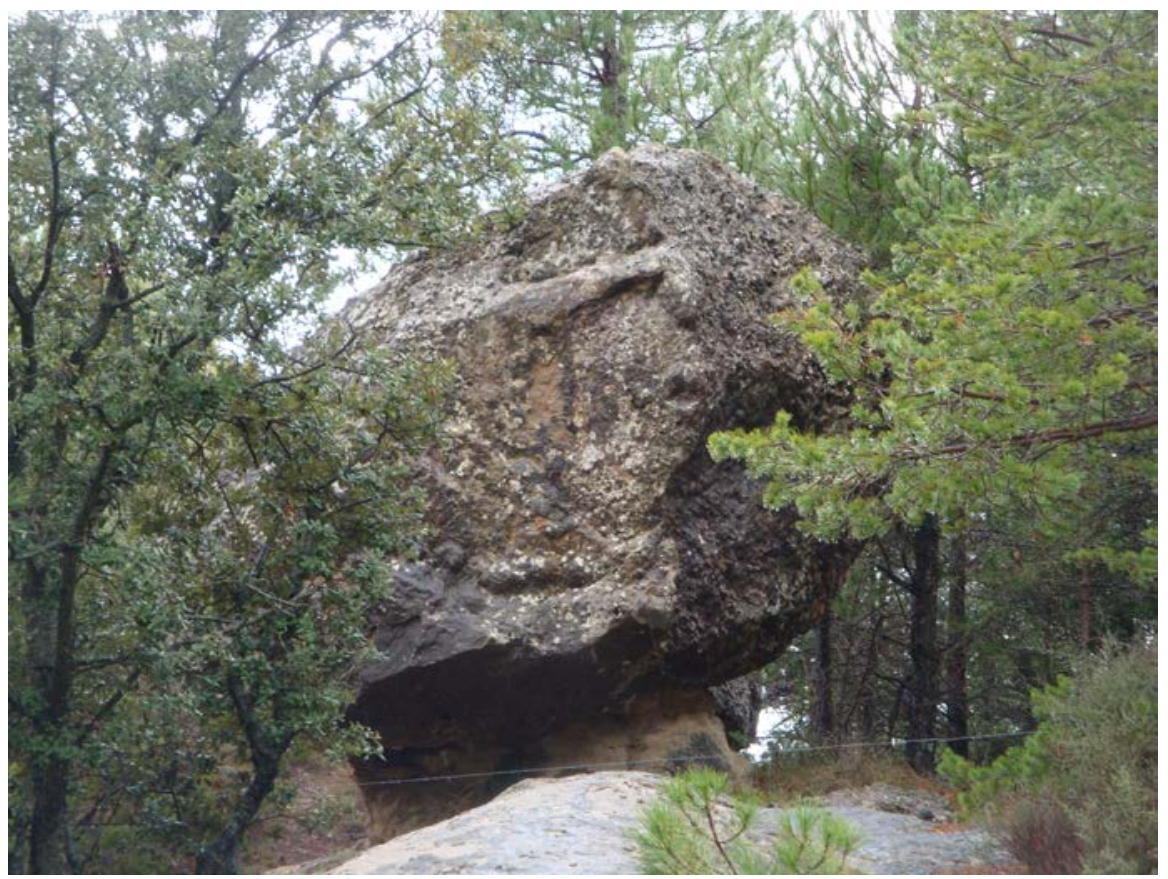

Fotografia 10. El "torm" de Sant Sadurní del Cint

\subsection{Parada 11 - Condicional. Carretera a Sant Lleïr, immediacions del Mercadal, (terme municipal de l’Espunyola, comarca del Berguedà). (Full 292).}

Des de la parada anterior, és necessari continuar baixant. En arribar a la cruïlla d'on surt la carretera cap a Sant Lleïr, la podem agafar fins arribar a les immediacions del Mercadal. Aquí podem fer una nova aturada, a uns $4 \mathrm{Km}$ de l'anterior.

En aquest tram, hem trobat afloraments dels nivells de gresos i de calcolutites de tonalitats ocres, les quals pertanyen a la Formació Solsona. Aquests són els materials que apareixen per l’indret de la present aturada.

Des d'aquest indret, es poden tornar a observar els nivells de conglomerats que formen part dels relleus de la Serra de Busa i alhora del Tossals de Vilella.

\subsection{Parada 12. Immediacions de l'ajuntament de l'Espunyola, (terme municipal de I’Espunyola, comarca del Berguedà). (Full 292).}

Després de realitzar l'aturada anterior, sols queda acabar de baixar per la carretera local, per tal d'arribar a la cruïlla amb la carretera autonòmica C - 26. En trobar-la, ens caldrà anar cap al poblet de l'Espunyola, per on realitzarem la darrera aturada d'aquest itinerari. Així, des de I'anterior, haurem recorregut uns $5 \mathrm{Km}$ més.

En aquest recorregut, hem tornat a trobar afloraments de les calcolutites i gresos de la Formació Solsona. Aquests son els materials que afloren per l'indret de la present aturada. 
Des d'aquest indret, mirant cap el Nord i cap el NE, es poden veure els relleus de la coneguda "cuesta de Capolat". (fotografia 11).

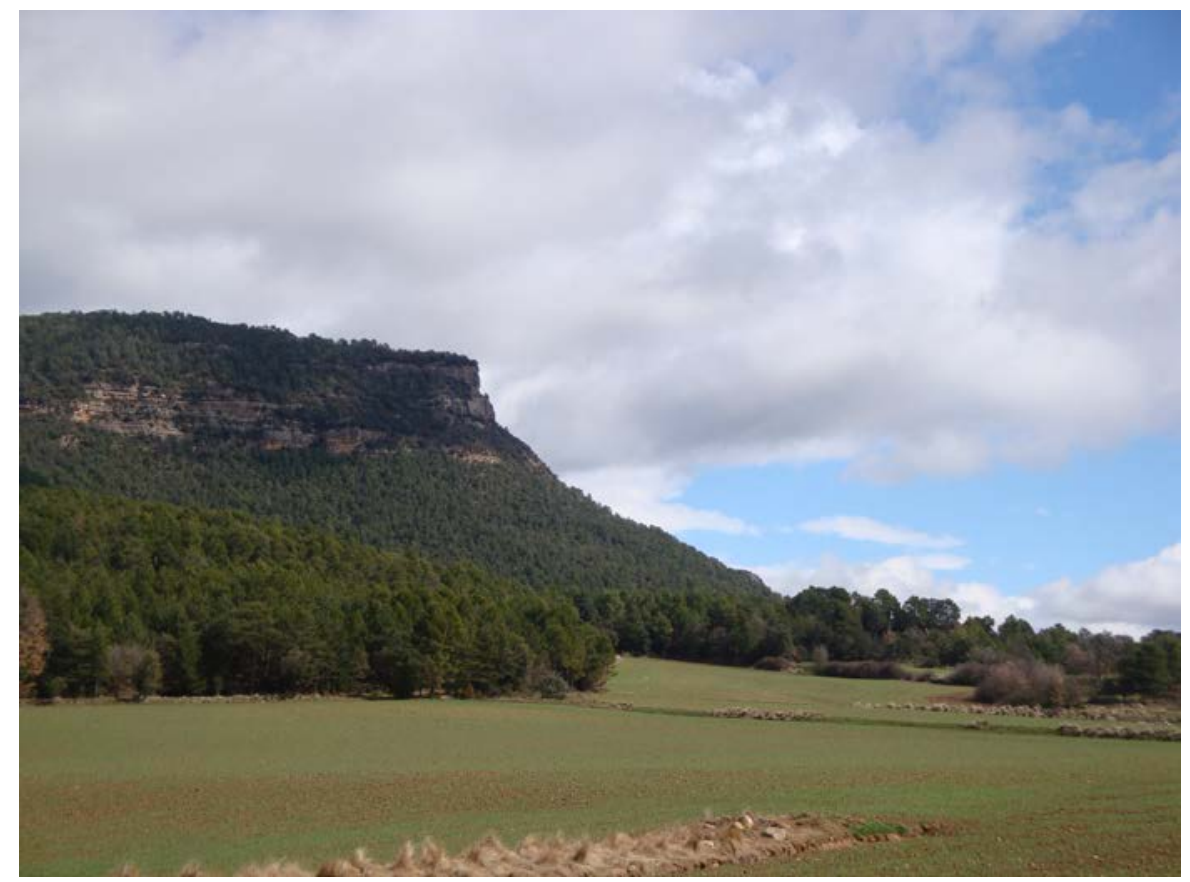

FOTOGRAFIA 11. Relleus de "cuesta de Capolat", per sobre de I’Espunyola

En aquest indret finalitza l'itinerari

\section{Bibliografia}

GUIMERÀ, J. et altri (1992).- Geologia (II), Història Natural dels Països Catalans, Vol. 2, 547 pag. Enciclopèdia Catalana, S.A. Barcelona.

IGME (1994a).- Explicació del Mapa Geologico de España, a escala 1:50.000 (full 255, la Pobla de Lillet). Inst. Tecnol- y GeoMinero de España. Minist. Indústria. Madrid.

IGME (1994b).- Explicació del Mapa Geologico de España, a escala 1:50.000 (full 293, Berga). Inst. Tecnol- y GeoMinero de España. Minist. Indústria. Madrid.

MASACHS, V. et altri (1981).- Itineraris Geològics: Anoia, Bages, Berguedà i Solsonès. Centre d'estudis Geològics de Manresa. Caixa d'estalvis de Manresa. Manresa.

MATA-PERELLÓ, J. M. (1984).- Els minerals del Berguedà. revista Xaragall, nº 3, 38 pag. Manresa. 
MATA-PERELLÓ, J. M. (1991).- Els Minerals de Catalunya. Arxius de la Secció de Ciències de I'Institut d'estudis Catalans, vol.47, 545 pàgines. Barcelona.

MATA-PERELLÓ, J. M. (1995).- Recerca a través de la geografia física de set comarques de la Catalunya Central. Pub. Museu de Geologia de la UPC, 168 pàgines. Manresa.

MATA-PERELLÓ, J. M. (1996a).- Selecció d'itineraris geològics i mineralògics pel Berguedà, i per les seves comarques veïnes. Pub. Universitat Catalana d’Estiu de la Natura. 52 pàgines. Berga.

MATA-PERELLÓ, J. M. (1997a).- Recerca Geològica i Mineralògica pel Berguedà i pel Ripollès: des de Berga a la Nou i a Malanyeu, i des de la Pobla de Lillet a Campdevànol. Inèdit, 10 pàgines. Manresa.

MATA-PERELLÓ, J. M. (1997b).- Recerca geològica i mineralògica per la comarca del Berguedà: des de Pedret i la Baells a la Pobla de Lillet, tot passant per la Nou i Catllaràs, Inèdit. 14 pag. Manresa

MATA-PERELLÓ, J.M. (2004).- Recerca geològica i mineralògica per la comarca del Berguedà: des de Pedret i la Baells a Guardiola del Berguedà, tot passant per la Nou. Inèdit. 9 pag. Manresa

MATA-PERELLÓ, J.M. (2007a).- Recerca geològica i mineralògica per la comarca del Berguedà: des del Santuari de Queralt a Sant Quirze del Pedret i la Baells, i a la Pobla de Lillet i Riutort. Inèdit. 12 pag. Manresa

MATA-PERELLÓ, J.M. (2007b).- Recerca geològica i mineralògica per les comarques del Berguedà i del Ripollès: des de Sant Quirze del Pedret i la Baells a Sant Jaume de Frontanyà, la Pobla de Lillet i a Campdevànol. Inèdit. 8 pàgines. Manresa

MATA-PERELLÓ, J.M. (2010).- Recerca geològica i mineralògica per la comarca del Berguedà: des de Sant Quirze del Pedret al Santuari de Queralt i a la Redonella. Inèdit, 10 pag. Manresa

MATA-PERELLÓ, J.M. (2011).- Recerca geològica i mineralògica per la comarca del Berguedà: des de Sant Quirze del Pedret al Santuari de Queralt, a la Rodonella i a Riutort. Inèdit. 10 pàgines. Manresa

MATA-PERELLÓ, J.M. (2012).- Recerca geològica i mineralògica per la comarca del Berguedà: des de Sant Quirze del Pedret al Santuari de Queralt a Baells, Vilada, Sant Jaume de Frontanyà i a la Pobla de Lillet. Inèdit. 14 pàgines. Manresa

MATA-PERELLÓ, J.M. (2013).- Recerca geològica i geoambiental per les comarques del Berguedà i del Solsonès: des de Berga i el Santuari de Queralt a Llinars, Guixers i a Sant Llorenç de Morunys. Inèdit. 16 pàgines

MATA-PERELLÓ, J.M. i SANZ BALAGUÉ, J. (1991).- Guia de determinació dels minerals. Països Catalans i Altres. Edic. Parcir. Manresa.

RIBA ARDERIU, O. et altri (1976).- Geografia Física dels Països Catalans. Edit Ketres. Barcelona 